\title{
Synthesis of Bioactive Barbituric Acid Derivatives using Microwave Irradiation Method
}

\author{
Mst. Khodeza Khatun*, Sharif M. Al-Reza, M. A. Sattar \\ Department of Applied Chemistry and Chemical Technology, Islamic University, Kushtia-7003, \\ Bangladesh \\ shima_acct@yahoo.com
}

\begin{abstract}
The research work was involved in rapid and efficient procedure for the attachment of barbituric acid with arylidene acetophenone under microwave irradiation (MWI) and conventional heating. The result showed that the time was reduced from the conventional 24 hours to 5-10 minutes. In conventional heating, the yield of the compounds 2a-2e were very poor (77-81\%), but in MWI methods the yields were observed 96-98\% which was comparatively too high. The structures of the compounds were characterized by FT-IR, ${ }^{1} H$-NMR spectral data. The antimicrobial and cytotoxic activities of the synthesized compounds were also investigated. All the tested bacteria revealed the zone of inhibition were $6-13 \mathrm{~mm}$ where sample concentration was $100 \mu \mathrm{g}$ disc ${ }^{-1}$. However, cytotoxic analysis, the mortality $49-95 \%$ were appeared when sample concentration were 0.78 -

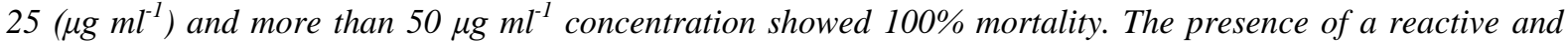
unsaturated ketone function in synthesized compounds was found to be responsible for their potential antimicrobial and cytotoxic activity.
\end{abstract}

Keywords: Microwave irradiation (MWI), Barbituric acid derivatives, Arylidene acetophenone, Antimicrobial and Cytotoxic activity

\section{INTRODUCTION}

Microwave technology has become a powerful tool in organic synthesis, since by employing this technique it is generally possible to prepare organic compounds very fast, with high purity and better yields compared to other more conventional methods [1-3]. Barbituric acid, chemically 2,4,6trioxohexahydropyrimidine, a cyclic amide used as the parent compound to produce barbiturates that act as central nervous system depressants. Barbituric acid itself does not give sedative and hypnotic effects but the substituted derivatives with alkyl or aryl group at position 5 provide effects. The derivatives of barbituric acid have especial place in pharmaceutical chemistry. Their biological activities range from classical applications in medical treatments as sedative, hypnotic, anticonvulsant, antiplasmodic and local anaesthetic drugs [4,5]. It has also more recent reports indicated that they have applications in anti-tumor, anti-cancer and anti-osteoporosis treatments [6,7].

A large number of reports are available on the reactions of barbituric acid and with carbonyl compounds-aldehydes, ketones and ester [8-10]. But it is observed that very little extent of work has been done on the reactions of barbituric acid with $\alpha, \beta$-unsaturated carbonyl systems. Although various routes for the synthesis of these compounds have been described, the majority of them involve a number of steps and the yields are poor [10]. Therefore, considering the necessity of efficient method development for the synthesis of barbituric acid derivatives, we synthesizes the barbituric acid derivatives using MWI which is relatively in good yields and to find out the potential biological activities of these compounds.

\section{EXPERIMENTAL}

\subsection{Apparatus}

The microwave oven used for this study was classic white ProLine Micro Chef ST44 (720 W, 2450 $\mathrm{MHz}$ ) which measures $38.2 \mathrm{~cm}$ (Height) $\times 52.6 \mathrm{~cm}$ (Width) $\times 34.5 \mathrm{~cm}($ Depth), with nine power settings. Melting point was uncorrected and was measured with electric-melting point apparatus. 


\subsection{Chemicals}

Aromatic aldehydes (benzaldehyde,4-chlorobenzaldehyde and 4-methoxybenzaldehyde), acetoph enones (acetophenone, 4-chloroacetophenone and 4-hydroxyacetophenone), barbituric acid was used for this experiment. $3 \mathrm{M} \mathrm{NaOH}, 95 \%$ ethanol, rectified sprit and water were used as solvents. All chemicals were used of commercial grade (Mark, Germany) without further purification.

\subsection{Product Analysis}

FT-IR spectrum (KBr) was obtained on a Fourier transform spectrometer (FTIR-8300). The ${ }^{1} \mathrm{H}-\mathrm{NMR}$ spectra was obtained at room temperature using chloroform-d $\left(\mathrm{CDCl}_{3}\right)$ with a JEOL EX 270 spectrophotometer at $270 \mathrm{MHz}$. The product was characterized by FT-IR, ${ }^{1} \mathrm{H}-\mathrm{NMR}$ spectra and compared their melting point with the literature value.

\subsection{Rate Enhancements}

The rate enhancement for comparable microwave and conventionally heated reactions was calculated by using identical concentration of the following manner:

Rate enhancement $=($ conventional reaction time/microwave reaction time $)$

Where, for the reactions the conventional reaction time and microwave reaction time were taken to the same extent of completion. In the present work, the reactions were carried out by following a general procedure [11-13].

\subsection{Synthesis of Barbituric acid derivatives (2a-2e)}

\subsubsection{The Reflux Condition (Conventional Method)}

A mixture of arylidene acetophenone (1a-1e) $(0.005 \mathrm{~mol})$ and barbituric acid $(0.005 \mathrm{~mol})$ were dissolved in rectified spirit $(25 \mathrm{ml})$ and water $(25 \mathrm{ml})$ in a $250 \mathrm{ml}$ round-bottomed flask. The flask was equipped with a refluxing condenser placed in a paraffin oil bath on a magnetic stirrer. The reaction mixture was refluxed for 18 hours and the course of the reaction was followed by TLC on silica gel plates (eluting solvent, Pet. ether: EtOAc; 5:1). The mixture was allowed to cool and the solid separated out was dried in air and recrystallized from hot rectified spirit.

\subsubsection{Microwave Irradiation Methods (MWI)}

In a $250 \mathrm{ml}$ conical flask an equimolar mixture of barbituric acid (2) (0.005 mol) and arylideneacetphenone (1a-1e) $(0.005 \mathrm{~mol})$ were dissolved in $25 \mathrm{ml}$ rectified spirit and $25 \mathrm{ml}$ water. The mixture was irradiated with microwave at different power level for several minutes and the progress of the reaction was followed by TLC on silica gel plate (eluting solvent, Pet. Ether: EtOAc; 5:1). The reaction mixture was cooled and the solid was separated out by filtration and recrystallized from hot rectified spirit. The purity of the product was checked by TLC.

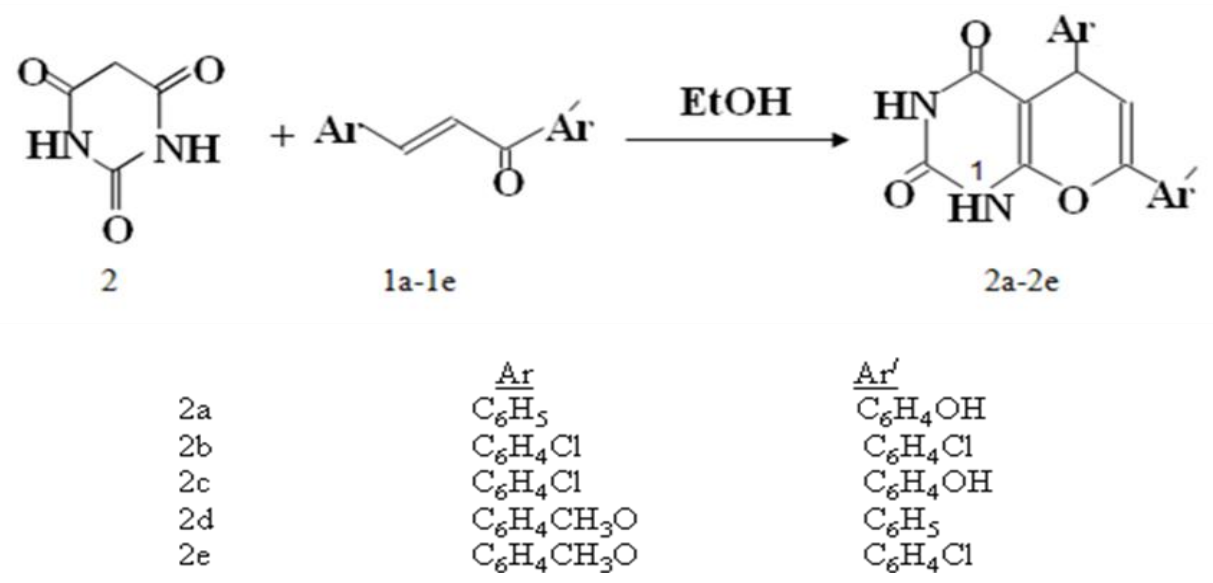

Scheme1. Synthesis of barbituric acid derivatives (2a-2e)

5-phenyl-7-(4-hydroxyphenyl)-1,2,3,4-tetrahydro-2,4-dioxo-5H-pyrano[2,3-d]pyrimidine (2a): Powder solid, color: whitish; melting point: $192-194{ }^{\circ} \mathrm{C}$; IR, v:3500, 3155, 3030, 1710, 1620, 1446, $1100(\mathrm{KBr}) \mathrm{cm}^{-1} ;{ }^{1} \mathrm{HNMR}\left(\mathrm{CDCI}_{3}\right) \delta: 11.02(\mathrm{~m}, 2 \mathrm{H}, \mathrm{NH}), 7.69-7.04(\mathrm{~m}, 9 \mathrm{H}, \mathrm{Ar}-\mathrm{H}), 4.82(\mathrm{~s}, 1 \mathrm{H}, \mathrm{Ar}-$ $\mathrm{OH}), 5.89(\mathrm{~d}, 1 \mathrm{H}, 6-\mathrm{H}), 4.49(\mathrm{~d}, 1 \mathrm{H}, 5-\mathrm{H})$. 
5,7-di-(4-chlorophenyl)-1,2,3,4-tetrahydro-2,4-dioxo-5H-pyrano [2,3-d]pyrimidine (2b):

Powder solid, color: whitish; melting point: $186-188^{\circ} \mathrm{C}$; IR $v: 3155,3010,1710,1620,1450,1103$, $780(\mathrm{KBr}) \mathrm{cm}^{-1} ;{ }^{1} \mathrm{HNMR}\left(\mathrm{CDCI}_{3}\right) \delta: 10.96(\mathrm{~m}, 2 \mathrm{H}, \mathrm{NH}), 7.50-6.93(\mathrm{~m}, 8 \mathrm{H}, \mathrm{Ar}-\mathrm{H}), 5.32(\mathrm{~d}, 1 \mathrm{H}, 6-\mathrm{H})$, $4.41(\mathrm{~d}, 1 \mathrm{H}, 5-\mathrm{H})$.

5-(4-chlorophenyl)-7-(4-hydroxyphenyl)-1,2,3,4-tetrahydro-2,4-dioxo-5H-pyrano[2,3-

d]pyrimidine (2c): Powder solid, color: whitish; melting point: $274-276{ }^{\circ} \mathrm{C}$; IR $v$ : $3700,3155,1710$, 1620, 1435, 1100, $775(\mathrm{KBr}) \mathrm{cm}^{-1} ;{ }^{1} \mathrm{HNMR}\left(\mathrm{CDCI}_{3}\right) \delta: 10.96(\mathrm{~m}, 2 \mathrm{H}, \mathrm{NH}), 7.56-6.93(\mathrm{~m}, 8 \mathrm{H}, \mathrm{Ar}-\mathrm{H})$, 4.71(s, 1H, Ar-OH), 5.79(d, 1H, 6-H), $4.42(\mathrm{~d}, 1 \mathrm{H}, 5-\mathrm{H})$.

5-(4-methoxyphenyl)-7-phenyl-1,2,3,4-tetrahydro-2,4-dioxo-5H-pyrano[2,3-d]pyrimidine (2d): Powder solid, color: whitish; melting point: $264-266{ }^{\circ} \mathrm{C}$; IR $v: 3155,, 1710,1620,1444,1261,1111$, $655(\mathrm{KBr}) \mathrm{cm}^{-1} ;{ }^{1} \mathrm{HNMR}\left(\mathrm{CDCI}_{3}\right) \delta: 11.01(\mathrm{~m}, 2 \mathrm{H}, \mathrm{NH}), 7.80-7.04(\mathrm{~m}, 9 \mathrm{H}, \mathrm{Ar}-\mathrm{H}), 5.83(\mathrm{~d}, 1 \mathrm{H}, 6-\mathrm{H})$, $4.43(\mathrm{~d}, 1 \mathrm{H}, 5-\mathrm{H}), 3.34\left(\mathrm{~s}, 3 \mathrm{H}, \mathrm{CH}_{3} \mathrm{O}\right)$.

\section{5-(4-methoxyphenyl)-7-(4-chlorophenyl)-1,2,3,4-tetrahydro-2,4-dioxo-5H-pyrano[2,3-}

d]pyrimidine (2e): Powder solid, color: whitish; melting point: $256-258{ }^{\circ} \mathrm{C}$; IR $v$ : $3170,3100,1710$, $1685,1620,1508,1423,1253,743$. (KBr) $\mathrm{cm}^{-1} ;{ }^{1} \mathrm{HNMR}\left(\mathrm{CDCI}_{3}\right) \delta: 10.96(\mathrm{~m}, 2 \mathrm{H}, \mathrm{NH}), 7.56-6.93$ $(\mathrm{m}, 8 \mathrm{H}, \mathrm{Ar}-\mathrm{H}), 5.74(\mathrm{~d}, 1 \mathrm{H}, 6-\mathrm{H}), 4.39(\mathrm{~d}, 1 \mathrm{H}, 5-\mathrm{H}), 3.37\left(\mathrm{~s}, 3 \mathrm{H}, \mathrm{CH}_{3} \mathrm{O}\right)$.

\subsection{Bioassay of Synthesized Compounds}

\subsubsection{Antimicrobial Activities}

\section{Microorganisms}

The microorganisms used for the experiment were collected as pure culture from the instituted of Food Science and Technology, BCSIR, Dhaka, Bangladesh. Aspergillus niger and Aspergillus flavus were taken for the anti-fungal activity test. Cultures of each fungal species were maintained on potatodextrose agar (PDA) slants and stored at $4^{\circ} \mathrm{C}$ and performed by disc diffusion method [14]. On the other hand, the organisms Staphylococcus aureus, Bacillus megaterium, Escherichia coli and Pseudomonas aeruginosa were used for anti-bacterial activity test. Active cultures for experimental use were prepared by transferring a loopful of cells from stock cultures to flasks and inoculated in Luria-Bertani (LB) broth medium at $37^{\circ} \mathrm{C}$ for 24 hours. Cultures of each bacterial strain were maintained on LB agar medium at $4^{\circ} \mathrm{C}[15]$.

\section{Preparation of Discs}

The antimicrobial activity was performed as the methods described previously [16]. Three types of discs were used for anti-bacterial and anti-fungal screening. Measured amount of each test sample was dissolved in specific volume of solvent to obtain the desired concentrations in an aseptic condition. Then discs were soaked with solutions of test samples and dried. Standard discs were used as positive control to ensure the activity of standard antibiotic against the test organisms as well as for comparison of the response produced by the known anti-bacterial and anti-fungal agent with that of produced by the test sample. In this investigation, kanamycin $\left(30 \mu \mathrm{g} \mathrm{disc}^{-1}\right)$ and ketoconazole $(30 \mu \mathrm{g}$ disc $^{-1}$ ) were used as standard reference disc for anti-bacterial and anti-fungal test, respectively. Blank discs were used as negative control which ensures that the residual solvents (left over the discs even after air-drying) and the filter papers were not active themselves.

\section{Diffusion and Incubation}

The sample discs, the standard antibiotic discs and the control discs were placed gently on the previously marked zones in the agar plates pre-inoculated with test bacteria and fungi. The plates were then kept in a refrigerator at $4^{\circ} \mathrm{C}$ for about 24 hours to allow sufficient diffusion of the materials from the discs to the surrounding agar medium. The plates were then inverted and kept in an incubator at $37^{\circ} \mathrm{C}$ for 24 hours for bacteria and at $28 \pm 2{ }^{\circ} \mathrm{C}$ for 48 hours for fungi. After incubation, the antimicrobial activities of the test materials were determined by measuring the diameter of the zones of inhibition in millimeter with transparent scale.

\subsubsection{Cytotoxicity Bioassay}

The cytotoxic activity was performed as described previously [17]. The test samples were dissolved in dimethyl sulfoxide (DMSO) and serial dilution were made as 100, 50, 25, 12.5, 6.25, 3.125, 1.563, 
$0.781 \mu \mathrm{g} \mathrm{ml}^{-1}$. Then each of these test solutions was added to test tubes containing 10 shrimps in simulated brine water $(5 \mathrm{ml})$ and incubated at room temperature for 24 hours. After 24 hours, the mortality percentages of the shrimps were calculated.

\section{RESULTS AND DiscuSSION}

The final products $2 \mathrm{a}-2 \mathrm{e}$ were obtained by the condensation reactions between the primary product (1a-1e) and barbituric acid (2) under conventional heating and were completed in 18 hours with moderate yield, whereas the same reactions under MWI method gave excellent yield within few minutes of irradiation. The structural assignment of 2a-2e was based on spectroscopic data. The FTIR data of the compounds 2a-2e showed sharp as well as broad bands in the range $\left(v_{\max }\right) 3155-3100$ $\mathrm{cm}^{-1}$ indicating the presence of $\mathrm{N}-\mathrm{H}$ group. The absorption bands at $1710-1680 \mathrm{~cm}^{-1}$ indicating the presence of $\mathrm{C}=\mathrm{O}$ group. The bands at $1620-1505 \mathrm{~cm}^{-1}$ were assigned to $\mathrm{C}=\mathrm{C}$ of aromatic rings and $\mathrm{C}=\mathrm{N}$ of the conjugated form of barbituric acid part. $1460-1400 \mathrm{~cm}^{-1}$ were assigned to $\mathrm{C}-\mathrm{C}$ stretching. The bands at $3700-3500 \mathrm{~cm}^{-1}$ indicating the presence of Ar-OH group, $800-600 \mathrm{~cm}^{-1}$ were assigned to aromatic $\mathrm{C}-\mathrm{Cl}$ group and $1265-1240 \mathrm{~cm}^{-1}$ indicates $\mathrm{Ar}-\mathrm{CH}_{3} \mathrm{O}$ group.

The ${ }^{1} \mathrm{H}-\mathrm{NMR}$ spectrum of the synthesized compounds showed the $\mathrm{N}-\mathrm{H}$ protons were strongly deshielded at $\delta 11.06-10.96(\mathrm{~d})$. The proton at position 6 appeared as $\delta 5.89-5.32(\mathrm{~d})$, the 5-H proton appeared as $\delta$ 4.49-4.39 (d). Ar-H group at $\delta$ 7.80-6.93 (m), Ar-OH group at $\delta 4.82-4.71(\mathrm{~s})$ and Ar$\mathrm{CH}_{3} \mathrm{O}$ group at $\delta 3.37-3.34$ (s). All the FT-IR, ${ }^{1} \mathrm{HNMR}$ signals are identical to the known compound barbituric acid derivatives [18,19].

The impact of microwave irradiation and conventional heating for the synthesis of compound $2 \mathrm{a}-2 \mathrm{e}$ has been compared. Moreover, the \% yield and time on the reaction were also studied and the results summarized in (Table 1). Comparative analysis of percentage yields and total reaction time for all synthesised barbituric acid derivatives by both conventional method and microwave-assisted method was carried out to find out if microwave-assisted synthesis of barbituric acid derivatives adds any advantage or not. It was found that there is improvement in percentage yields of barbituric acid derivatives and also drastic reduction in total reaction time. By using microwave irradiation, reaction is possible within few minutes; and it also improves the yield. This would be highly advantageous for drug discovery in laboratories where small amounts of different analogues have to be synthesised in short periods of time. This is very useful for combinatorial synthesis of new libraries of compounds. Microwave-assisted synthesis is quicker, high yielding, environment friendly and shows cleaner chemistry.

Table1. Comparative study for the synthesis of barbituric acid derivatives

\begin{tabular}{|c|c|c|c|c|c|}
\hline \multirow{2}{*}{ Compounds } & \multicolumn{2}{|c|}{ Conventional method } & \multicolumn{3}{|c|}{ Microwave method } \\
\cline { 2 - 6 } & Time (hr) & Yield (\%) & Time (min) & Power (W) & Yield (\%) \\
\hline 2a & 18 & 78.00 & 8 & 320 & 95.96 \\
\hline 2b & 18 & 79.00 & 7 & 80 & 97.03 \\
\hline 2c & 18 & 81.00 & 6 & 80 & 98.45 \\
\hline 2d & 18 & 77.00 & 6 & 160 & 98.00 \\
\hline 2e & 18 & 79.00 & 6 & 80 & 97.00 \\
\hline
\end{tabular}

Table2. Antimicrobial activities of the synthesized compounds

\begin{tabular}{|c|c|c|c|c|c|c|}
\hline \multirow{2}{*}{$\begin{array}{c}\text { Tested } \\
\text { Sample }\end{array}$} & \multicolumn{5}{|c|}{ Name of Bacteria } & \multicolumn{2}{c|}{ Name of Fungi } \\
\cline { 2 - 7 } & S. aureus & B. megaterium & P. aeruginosa & E. coli & A. niger & A. flavus \\
\cline { 2 - 7 } & \multicolumn{7}{|c|}{ Diameter of Zone of Inhibition (mm) } \\
\hline 2a & 13 & 12 & 10 & 8 & 16 & 17 \\
\hline 2b & 13 & 13 & 11 & 9 & 14 & 16 \\
\hline 2c & 6 & 7 & - & - & 14 & 16 \\
\hline 2d & 10 & 9 & 9 & 7 & 13 & 16 \\
\hline 2e & 11 & 12 & 12 & 7 & 12 & 16 \\
\hline Ketoconazole & - & - & - & - & 22 & 26 \\
\hline Kanamycin & 28 & 29 & 28 & 27 & - & - \\
\hline
\end{tabular}

The synthesised barbituric acid derivatives (2a-2e) were screened for their antibacterial activity against both Gram positive and Gram negative organisms by disc diffusion method using Kanamycin and Ketoconazole as the standard and methanol as the vehicle. Staphylococcus aureus, Bacillus 
megaterium, Escherichia coli and Pseudomonas aeruginosa are used as the organisms. Screenings for the newly synthesized compounds were done at concentrations $100 \mu \mathrm{g} \mathrm{disc}^{-1}$. Staphylococcus aureus and Bacillus megaterium were found to be resistant to all the compounds. The diameters of zone of inhibition were 6-13 mm. However, the two Gram negative organism namely Escherichia coli and Pseudomonas aeruginosa were showed zone of inhibition 7-12 $\mathrm{mm}$ resistant to most of the compounds tested (Table 2).

All the synthesized compounds were also screened for antifungal activity against Aspergillus niger and Aspergillus flavus by disc diffusion method using ketoconazole $\left(30 \mu \mathrm{g} \mathrm{disc}{ }^{-1}\right)$ as the standard and methanol as the vehicle. As shown in Table 2 both the fungal strains were found to be moderately sensitive to all the tested compounds.

The cytotoxic activities of the synthesized compounds were determined by using brine shrimp lethality bioassay. The mortality percentages for all the tested samples were found to be very high. Some compounds showed $100 \%$ mortality at very low concentration as shown in Table 3. Sample concentration $\left.0.78-25(\mu \mathrm{g} \mathrm{ml})^{-1}\right)$ showed the mortality of $49-95 \%$, whereas $50-100\left(\mu \mathrm{g} \mathrm{ml}^{-1}\right)$ concentration showed $100 \%$ mortality. From this study, it is evident that all the test samples were lethal to brine shrimp nauplii. These positive results suggested that they may contain antitumor or pesticidal activity.

Table3. Cytotoxic activities of the synthesized compounds

\begin{tabular}{|c|c|c|c|c|c|c|c|c|c|}
\hline \multirow{2}{*}{$\begin{array}{c}\text { Tested } \\
\text { Sample }\end{array}$} & \multicolumn{7}{|c|}{ Sample Concentration $\left(\mu \mathrm{g} \mathrm{m}^{-1}\right)$} \\
\cline { 2 - 9 } & 0.78 & 1.56 & 3.125 & 6.25 & 12.5 & 25 & 50 & 100 \\
\hline & \multicolumn{7}{|c|}{ Mortality (\%) } \\
\hline 2a & 49 & 78 & 89 & 89 & 89 & 95 & 100 & 100 \\
\hline 2b & 69 & 89 & 89 & 89 & 89 & 93 & 100 & 100 \\
\hline 2c & 57 & 79 & 89 & 89 & 90 & 90 & 100 & 100 \\
\hline 2d & 68 & 68 & 89 & 89 & 89 & 93 & 100 & 100 \\
\hline 2e & 54 & 57 & 79 & 89 & 89 & 93 & 100 & 100 \\
\hline
\end{tabular}

\section{CONCLUSiON}

The preparation procedure followed in this work for the synthesis of schiff base offers reduction in reaction time, excellent yields without formation of undesirable side products, operation simplicity, cleaner reaction and easy work-up in Microwave-assisted syntheses. These synthesis apart from reducing the use of organic solvents from work up step, also gave improved yield as compared to the conventional heating with reaction time reduced from hours to minutes. Low amount of chemicals were used making the method of synthesis environmental friendly. In other words, as a modest work of green chemistry, it is a viable and feasible method for performing the synthesis of drug, intermediates and chemicals.

\section{REFERENCES}

[1] Loupy A., Microwaves in Organic Synthesis, Wiley-VCH, Weinheim, (2002).

[2] Hayes B.L., Microwave Synthesis: Chemistry at the Speed of Light, CEM Publishing, Matthews, NC, (2002).

[3] Kappe C.O., Stadler A., Microwaves in Organic and Medicinal Chemistry, Wiley-VCH, Weinheim, (2005).

[4] Tanka K., Cheng X., Yoneda F., Oxidation of thiol with 5-arylidene-1,3 dimethylbarbituric acid: application to synthesis of unsymmetrical disulfide, Tetrahed., 44 (1988) 3241-3249.

[5] Sokmen B.B., Ugras S., Sarikaya H.Y., Ugras H.I., Yanardag R., Antibacterial, antiurease, and antioxidant activities of some arylidene barbiturates, App. Biochem. Biotech., 171(8) (2013) 2030-2039.

[6] Jones G., In: Organic Reactions, New York: Wiley, 1967, pp. 204-599.

[7] Khajuria R.K., Jain S.M., Dhar K.L., Studies on cycloaddition reactions of 2,4 dihydroxy-3undecyl-1, 4-benzoquinone (embelin) and 2,3-dimethyl buta-1,3-diene, Indian J. Chem., 35B (1996) 860.

[8] Ahluwalia V.K., Sahay R., Das U., One-pot facile synthesis of some new 9,10 dihydroacridine derivatives, Indian J. Chem., 38 (9) (1999) 1136-1138. 
[9] Ahmed M.G., Romman U.K.R., Ahmed S.M., Akhter K., Halim M.E., Salauddin M., A study on the synthesis of 5, 7-Diaryl-1,2,3,4-tetrahydro-2,4-dioxo-5H-pyrano [2,3- $d$ ] pyrimidines, Bangladesh J. Sci. Ind. Res., 41(3-4) (2006) 119-128.

[10] Nasrin D., Islam N., Hoque F., Ferdous T., Farhana F.Z., Microwave assisted synthesis of pyrano [2, 3-d] pyrimidinone derivatives, Intern. J. Basic App. Sci., 12(05) (2012) 50-53.

[11] Vogel A.I., A Text Book of Practical Organic Chemistry, Forth Ed., Longman Group Ltd., London, 1978, pp. 796.

[12] Veeriah T., Sondu S., Interactive free-energy relationships in the os(viii) catalyzed oxidation of chalcones by acid bromate-A kinetic-study, Indian J. Chem., 35(12) (1996) 1073-1078.

[13] Ahmed M.G., Romman U.K.R., Akhter K., Halim M.E., Rahman M.M., Ahmed S.M., $\quad$ A one-step synthesis of 5,7-diaryl-1,5-dihydro (or 1,2,3,5-tetra-hydro)-pyrano [2,3-d] pyrimidin-2,4-diones ( or 2-thioxo-4-ones), Indian J. Chem., 5B (2011) 946-948.

[14] Siddiqui S.A., Islam R., Islam R., Jamal A.H.M., Parvin T., Rahman A., Chemical composition and antifungal properties of the essential oil and various extracts of Mikania scandens (L.) Willd, Arabia J. Chem., In Press, (2013).

[15] Al-Reza S.M., A. Rahman, J. Lee, S.C. Kang, Potential roles of essential oil and organic extracts of Zizyphus jujuba in inhibiting food-borne pathogens, Food Chem. 119 (2010) 981-986.

[16] Bauer A.W., Kirby W.M.M., Sherris J.C., Turck M., Antibiotic susceptibility testing by a standard single disc method, American J. Clin. Pathol., 45 (1960) 493-496.

[17] Meyer B.N., Ferrigni N.R., Putnam J.E., Jacobsen L.B., Nichols D.E., Malaughlin J.L., Brine Shrimp: A convenient general biossay for active plant constituents, Plant Med., 45 (1982) 31-32.

[18] A. Habibi, Z. Tarameshloo, A new and convenient method for synthesis of barbituric acid derivatives, J. Iranian Chem. Soc., 8(1) (2011) 287-291.

[19] Hosseini Y., Rastgar S., Heren Z., Büyükgüngörc O., Pesyan N.N., One-pot new barbituric acid derivatives derived from the reaction of barbituric acids with $\mathrm{BrCN}$ and ketones, J.Chinese Chem. Soc., 58 (3) (2011) 309-318. 